\title{
A Fellow's Perspective on the Threatened Closure of the Illinois Poison Center
}

\author{
Navneet Cheema
}

Published online: 12 June 2014

(C) American College of Medical Toxicology 2014

Over the past three decades, the number of drug poisonings has increased sixfold [1]. In 2008, for the first time since 1980, poisoning surpassed motor vehicle traffic-related deaths and became the leading cause of injury death in the USA. In 2012, the nation's 57 poison centers answered over 3.3 million calls [2]. Preventing poisoning deaths continues to be a national priority and is a goal of the Healthy People 2020 initiative [3]. Armed with these facts, it is baffling that the nation's oldest poison center is again under imminent threat of closure.

In the mid 1900s, the issue of childhood poisoning was thrust to the forefront of pediatric medicine. The American Academy of Pediatrics (AAP) found $49 \%$ of reported accidents involved poisonings, mainly from household products and medications [4]. The end of World War II saw an influx of novel consumer products including insecticides, polishes, and paints. While these products contributed to the urbanization of America, they also led to an increased number of accidental poisonings [4]. In 1949, 423 children died as a result of accidental poisonings as compared to only 46 in 2012 [2, 5]. There was a demand in the medical community to have a systematic way to address this newfound area of concern. Louis Gdalman, R.Ph, a staff pharmacist at St. Luke's Hospital in Chicago, had long recognized this need and already founded a $24-\mathrm{h}$ telephone consultation service a decade prior. Initially, most calls came from local physicians, but the service grew rapidly and soon calls flooded in from across the nation [4]. Meanwhile, Edward Press, M.D., a Chicago Pediatrician, was working with the AAP to open the nation's first poison center. This humble center opened in 1953 and consisted of a single desk and a lone phone. Gdalman and Press eventually joined forces and reached out to industry in an attempt to

N. Cheema $(\bowtie)$

Toxikon Consortium,

1900 West Polk Street, 10th Floor, Chicago, IL 60612, USA

e-mail: ncheema008@gmail.com index ingredients, toxicities, and treatment strategies for common exposures. Together they indexed over 9,000 commercial and consumer products, creating a database of information similar the modern day Poisindex ${ }^{\circledR}$, which was founded by Barry Rumack, M.D. [4, 6]. Poison centers rapidly gained popularity, with a peak of 661 centers in 1978, of which 102 were in Illinois [7]. However, by 1970, fewer than $6 \%$ of poison centers received more than ten calls a day [6]. For multiple reasons, including budget cutbacks and increasingly strict center certification criteria, the number of poison centers decreased rapidly. By 1997, there was only one poison center left in the state of Illinois, the Illinois Poison Center (IPC).

The IPC is an integral component of the state's crisis response system. There is no example more powerful than the Tylenol ${ }^{\circledR}$ cyanide murders. The famous cyanide Tylenol ${ }^{\circledR}$ murders took place in Chicago on September 29, 1982 [8]. Imagine a day where a 12-year-old schoolgirl, a new mother, and a postal worker all collapse and die within hours, the only unifying thread being Tylenol ${ }^{\circledR}$. Several other deaths quickly followed, leading to the discovery that all the victims had ingested cyanide-laced Tylenol ${ }^{\circledR}$. Panic struck Chicago and much of the country. Police drove through neighborhoods broadcasting warnings on loudspeakers, children were sent home from school, and trucks drove frantically through the city distributing amyl nitrite. What seemed like just another routine day at the IPC quickly became one of its busiest. Tony Burda, CSPI of over 30 years, recalls hearing the news on the radio and saying, "Holy $\mathrm{s}^{* * *}$, we're going to get killed!" and they did! The IPC, which at that time took between 40 and 60 calls a day, fielded nearly 800 calls that day. The phone rang non-stop, leaving the CSPIs unable to record detailed demographic data, simply marking hashes to track numbers [9]. The IPC was a critical component, working in conjunction with other emergency response teams in reassuring the public, transmitting reliable information, gathering data, and preventing widespread chaos. 
The modern day poison center serves many roles. It is a recognized authority on poisoning information, a source of healthcare savings, a center for community outreach, a critical component of toxicology education, and a tool for epidemiological surveillance. Poison centers are also an integral part of the healthcare system. For every dollar spent on the poison center, the return is $\$ 13.39$ [10]. Poison centers decrease healthcare costs, reduce hospital length of stay, and reduce work-loss days. The Lewin Report estimated that poison centers save 1.8 billion dollars per year in medical costs and productivity [10]. Miller and Lestina found that the average phone call to the poison center saved $\$ 175$ in health care spending [11]. The closing of poison centers has clear ramifications for the local healthcare system. The closure of the Michigan poison center in 2009 led to a $33 \%$ increase in ED visits for poisonings while a closure in Louisiana in 1988 led to a $42 \%$ increase [10]. Additional studies have also demonstrated that without a poison center, primary care physicians would refer about $82 \%$ percent of callers to 911 or an ED [12]. It has become increasingly evident that poison centers are critical to our health care system, yet there is no consensus on how they should be funded. The federal government is the beneficiary of about $37 \%$ of the cost savings and only pays $13 \%$ of the cost. Similarly, the private sector receives about $48 \%$ of the savings but pay only $25 \%$ [10]. Closure of the IPC would lead to an additional estimated 10,000 hospital admission days, 35,000 ED visits, and 50 million dollars in healthcare costs per year [13]. These numbers provide a numerical perspective but can never fully illustrate the intangible benefits of the IPC and its vital role in the community.

Poison centers have long been recognized for their epidemiologic surveillance and the detection of new outbreaks. Several examples nationally include cataloging symptoms and clinical effects of levamisole-contaminated cocaine, the H1N1 outbreak, and the Gulf oil spill [14]. A prominent recent example of IPC's involvement in detecting new drugs of abuse is "Operation Smoked Out". In 2009, the initial reports of synthetic cathinone and cannabinoid homologs first surfaced in the USA. The initial reports to the IPC occurred in March 2011. The poison center served as an early warning network about these new drugs and was a key component of helping decrease their availability in Illinois. The IPC and the Illinois Attorney General worked in conjunction to create "Operation Smoked Out". This program consisted of undercover buyers, analysis of purchased products, and educating business owners on the effects of these products. This program has been immensely successful, with over 80 retailers voluntarily giving up their supply of synthetic products and thereby preventing the sale of over $\$ 500,000$ worth of product. Prior to this program, the IPC had $33 \%$ more calls regarding synthetics compared to the national average, and after this program, IPC had $60 \%$ less calls compared to the national average [13]. This is just one example of the importance of poison centers in detecting new outbreaks, guiding healthcare providers, and working with local law enforcement and public health officials to prevent additional exposures and disseminate information.

A vital yet often underappreciated role of poison centers is the toxicological education of healthcare providers. In the era of poly-pharmacy, the opioid epidemic, and chemophobia, a fundamental understanding of toxicology is critical to nearly every specialty. Both personal experience and previous studies have demonstrated the immense contribution poison centers make to this formidable task [15-17]. The IPC plays a central role in the Toxikon Consortium toxicology rotation. The IPC has participated in training 1,336 residents, 522 medical students, and 38 medical toxicology fellows. Residents and students hail from a diverse background, including emergency medicine, pediatrics, occupational medicine, and pharmacy. Where would these students obtain toxicology education without the IPC? A previous study by Hays et al. demonstrated that only $4.9 \%$ of US and Canadian Medical Schools have a separate formal toxicology course and, on average, spend between 5 and $6 \mathrm{~h}$ teaching toxicology. Only $51 \%$ of medical schools have toxicologist on staff, further limiting the integration of toxicology into resident and medical student curriculum [18]. Additionally, the closure of a poison center would threaten associated medical toxicology fellowships, as this affiliation is required to be an ACGME accredited program.

The Illinois Poison Center is not the first to be threatened with closure and it will not be the last. Before it becomes another casualty of budget cuts, we must work to secure recognition of the IPC for its indisputable importance to our healthcare system. It has clearly demonstrated its role in cost savings, education, and public safety over its many decades of service, yet it holds the potential to permeate many other areas of healthcare. The IPC provides a quiet comfort that we have become accustomed to and one that may not be fully appreciated until it is gone.

\section{Source of Funding None.}

Conflicts of Interest None.

Previous Presentations None.

\section{References}

1. Warner M, Chen LH, Makuc DM, Anderson RN, Minino AM (2011) Drug poisoning deaths in the United States, 1980-2008. NCHS data brief (81): 1-8

2. Mowry JB, Spyker DA, Cantilena LR Jr, Bailey JE, Ford M (2013) 2012 annual report of the American Association of Poison Control Centers' National Poison Data System (NPDS): 30th annual report. Clin Toxicol (Phila) 51(10):949-1229 
3. Healthy People 2020. http://www.healthypeople.gov/2020/ topicsobjectives2020/objectiveslist.aspx?topicId $=24$

4. Botticelli JT, Pierpaoli PG (1992) Louis Gdalman, pioneer in hospital pharmacy poison information services. Am J Hosp Pharm 49(6): $1445-1450$

5. Bain K (1954) Death due to accidental poisoning in young children. J Pediatr 44(6):616-623

6. Committee on Poison Prevention and Control; Board on Health Promotion and Disease Prevention (HPDP); Institute of Medicine (IOM) (2004) Forging a poison prevention and control system. Washington, DC: The National Academies Press

7. Scherz RG, Robertson WO (1978) The history of poison control centers in the United States. Clin Toxicol 12(3):291-296

8. Dunea G (1983) Death over the counter. Br Med J (Clin Res) 286(6360):211-212

9. Burda T (2010) Recollections of the 1982 Chicago Tylenol ${ }^{\circledR}$-cyanide poisonings. http://ipcblog.org/2010/02/02/recollections-of-the-1982chicago-tylenol\%C2\%AE-cyanide-poisonings/. Accessed 12 May 2014

10. The Lewin Group (2012) Final report on the value of the poison center system. https://aapcc.s3.amazonaws.com/files/library/Value_of the Poison_Center_System_FINAL_9_26_2012_-_FINAL_FINAL FINAL.pdf. Accessed 5 May $201 \overline{4}$
11. Miller TR, Lestina DC (1997) Costs of poisoning in the United States and savings from poison control centers: a benefit-cost analysis. Ann Emerg Med 29(2):239-245

12. Austin T, Brooks DE, Welch S, Lovecchio F (2012) A survey of primary care offices: triage of poisoning calls without a poison control center. Int J Fam Med 2012:417823

13. Wahl M (2012) Synthetic drugs. Illinois Poison Center reports. http://illinoispoisoncenter.org/Synthietic_Drugs_ Whitepaper

14. Dart RC (2012) The secret life of America's poison centers. Ann Emerg Med 59(1):62-66

15. Cobaugh DJ, Goetz CM, Lopez GP, Dean BS, Krenzelok EP (1997) Assessment of learning by emergency medicine residents and pharmacy students participating in a poison center clerkship. Vet Hum Toxicol 39(3):173-175

16. Dayan AD (1989) Who needs toxicology? J R Soc Med 82(6):320-322

17. Lovejoy FH Jr, Edlin AI, Goldman P (1979) Utilization of the poison center for the teaching of clinical toxicology to medical and pharmacy students, housestaff, and health care professionals. Clin Toxicol 15(4):393-400

18. Hays EP Jr, Schumacher C, Ferrario CG, Vazzana T, Erickson T, Hryhorczuk DO, Leikin JB (1992) Toxicology training in US and Canadian medical schools. Am J Emerg Med 10(2):121-123 